\title{
Features of Identity of the Population of Afghanistan
}

\author{
Olga Ladygina*
}

Department of History and International Relations, Russian-Tajik Slavonic University, M.Tursunzoda str., 30, Dushanbe, 734025, Tajikistan

\begin{abstract}
The issues of identity of the population of Afghanistan, which is viewed as a complex selfdeveloping system with the dissipative structure are studied in the article. The factors influencing the development of the structure of the identity of the society of Afghanistan, including natural and geographical environment, social structure of the society, political factors, as well as the features of the historically established economic and cultural types of the population of Afghanistan, i.e. the Pashtuns and Tajiks are described. The author of the article compares the mental characteristics of the bearers of agriculture and the culture of pastoralists and nomads on the basis of description of cultivated values and behavior stereotypes. The study of the factors that influence the formation of the identity of the Afghan society made it possible to justify the argument about the prevalence of local forms of identity within the Afghan society. It is shown that the prevalence of local forms of identity results in the political instability. Besides, it constrains the process of development of national identity and articulation of national idea which may ensure the society consolidation. The relevance of such studies lies in the fact that today one of the threats of Afghanistan is the separatist sentiments coming from the ethnic political elites, which, in turn, negatively affects the entire political situation in the region and can lead to the implementation of centrifugal scenarios in the Central Asian states.
\end{abstract}

\section{Introduction}

Identity is a complex organization within which the following levels can be identified:

- micro-level is formed by the primordial components of identity, which represent an objective given and which do not depend on the will of the carriers. The primordial components of identity correspond to the local forms of social solidarity, such as family, clan, class, community;

- macro-level is formed by the instrumental components of identity with the help of which people achieve certain goals: social mobility, prevalence and preferences overcoming, social control, mutual services and solidarity;

- mega-level is comprised of the components of constructivism, which result from a purposeful activity of the elite. These components include civil (national) identity.

These levels somehow interrelate with each other. So, for example, the construction of identity, both on an individual and collective levels, is carried out using stable diagrams. Therefore, identity is the process of constructing primordiality, the success of which is determined by the set of connections with the objective reality. Social construction cannot but to take into account the needs of the population to feel themselves a member of a community with the history, tradition, cultural and historical memory, as well as sacred and timeless symbols.

The performed study is an attempt to investigate the factors that impede the formation of a national (civil) identity in Afghanistan the components of which are designed to regulate the diversity of the primordial level.

\section{Problem Statement}

Identity may contribute to the consolidation of society; however, it may also be a barrier on the way to its consolidation. Among various forms of social identity, the national identity is a domineering one. This is due to the fact that national interests are realized on its basis. Moreover, it is not only the interests of individual ethnic groups, but the interests of the entire population of the state, whose protection is possible due to the joint efforts of all members of the society. Thus, the national identity promotes the consolidation of the society, overcoming the interethnic differences. The prevalence of local forms of identity leads to an isolation and does not allow us to understand national interests. The analysis of the structure of identity and the identification of its features makes it possible to identify factors that impede the consolidation of the Afghan society and, hence, the stabilization of the political situation in the country.

\footnotetext{
* Corresponding author: friedrichii@mail.ru
} 


\section{Purpose of Study}

The purpose of the study is to reveal the features of the identity structure of the Afghan society. This goal implies not only the identification of dominant forms of identities, but also the conditions for the implementations of these forms.

\section{Research Methods}

The study of peculiarities of the identity structure of the Afghan society was conducted on the basis of synergetics principles, which make it possible to consider the object of analysis as a complex selforganized and open system. Such systems interact with the environment, providing an exchange with the energy / information. A complex network of relationships is an integral nonlinear environment. At the same time the external factors can both accelerate and restrain the process of making the system more complex (the development of the system). For the system of identity the external environment would be represented as a natural-biological, geographic environment, as well as a social and cultural system that has a metastable structure and retains its prototypical quality within a long period of time. The geographic environment is the basis for the functioning and development of society which determines the features of the economy, politics and history of the nation in many respects.

\section{Results and Discussion, Findings}

One of the reasons for the isolation of the population of Afghanistan is its natural and geographical positioning. The population of Afghanistan is a heterogeneous society. As far as the number of ethnic groups concerns, Afghanistan occupies one of the first places in the Near and Middle East. The country has over 10 nationalities and several dozen ethnic groups belonging to the Iranian, Indian, Turco-Mongol, Semito-Hamitic and Dravidian ethnic groups, as well as more than one hundred tribes and many tribal groups. In the south of the country there are large enclaves of Tajiks and Shiite-Hazaras. Besides, emigrants form their own ethnic groups. A. Knyazev notes that it is very difficult to determine the geography of settlement of Afghanistan ethnos [2]. Thus, the landscape and geographical location of the population of Afghanistan contributes to the prevalence of primary forms of group solidarity.

The heterogeneity of society is aggravated by high dispersity of the settlement of ethnic groups. During the implementation of the resettlement policy in the late XIX and early XX centuries, 62 thousand Pashtun families were relocated to the northern and central parts of the country. As a result 'in 1930s ... many villages in the districts of Kunduz and Khanabad, where Tajiks and Uzbeks used to live, were completely populated by Pashtuns. The same picture was observed in Cattagan in the areas of Tashkurgan, Aibak, and Khoja-Nahru. A large number of Pashtun families came to life in Badakhshan' [2]. One of the consequences resulting from it was the redistribution of land ownership in favor of Pashtuns. Thus, $10 \%$ of the best irrigated lands in the north of Afghanistan were owned by Pashtuns [5].

The consolidation of the society is hampered by the fact that practically all major peoples living in Afghanistan, apart from Hazaras, are separated. Yu.P. Laletin draws attention to the fact of predominance of the so-called divided nations in Afghanistan most of which were part of the neighboring states (Tajikistan, Uzbekistan, Turkmenistan, Kyrgyzstan, Kazakhstan, Iran, Pakistan, India, and China): Pashtuns, Baluchis, Tajiks, Uzbeks, Kazakhs, Turkmens, Kirghiz [5]. The ethno-demographic picture of the two largest ethnic groups in Afghanistan is as follows: the Pashtuns in Afghanistan amount to 8 to 9 million, and in Pakistan there are 13 to 14 million; Tajiks in Afghanistan amount to about 4 million, and in Tajikistan the number is equal to 3.5 million [2]. The separation of peoples gives them a craving for their foreign ethnic parts, preventing the national consolidation of the Afghan society and implementing the tool components of the identity.

Ethnic localization is complemented by the linguistic one, preventing the consolidation of the Afghan society. There are 30 languages on the territory of Afghanistan. Among them are Iranian, Indo-Aryan (Indian), Turkic and Nuristan (Dard) languages. The Hindu Kush ridges form the border of the distribution zones of two main languages, i.e. Pashto and Dari.

Religious, linguistic and cultural differences take place not only along the boundaries of the settlement of ethnic groups, but also within the ethnic formations [4]. The Pashtuns, most Tajiks, Uzbeks, Turkmen, Nuristanis, Baluchis, Arabs, part of the Charaimaks ( $85 \%$ of the total population) are united by the Hanifite sense of Sunnism. The mountain Tajiks of Badakhshan and Parvan (the Pripamir peoples), Kirghiz, some part of the Charaimaks (over 1 million people) are the Ismailis. The kizilbashi, afshary, teymuri belong to the Shiites; and the tribe of Turi, part of the Jaji, some clans of the tribe of Orakzai of Tirach, some tribes of the Bangash of the Upper Kurram and the clan of the Mani of the Afridi tribe belong to the Pashtuns. The Indian community is divided into the followers of Hinduism and Sikhism. Among the population, mainly in the Pashtun tribes, there are adherents of certain Sufi orders (Kadiriya, Nakshbandiya).

The religious factor imposes an imprint on the social organization of some peoples, increasing the isolation of the believer communities (among Hazaras, Sikhs, Indians, and mountain Tajiks), hampering the processes of intra-national consolidation.

There exists some enmity and contradictions between large tribal unions and separate tribes forming one community, which is the evidence of the stability of primary forms by a group of solidarity and the strength of the archaic forms of identity. So, for example, according to the mythological ideas of the Pushtuns, the ancestor of the Afghans is Kais, the grandchildren of who gave birth to the majority of the Pashtuns. Moreover, the Pashtuns and the Gilsais are the Pashtuns only on the maternal side. This legend caused the enmity and contradictions between the Pashtun tribes, 
preventing their consolidation. There was a constant feud between tribes because of the pastures, plots of land, water for irrigation, etc.

The stability of the local forms of identity is promoted by the stability of the patriarchal way of life, which leaves no place for the manifestation of independence, forming a socially infantile personality that is incapable of taking responsibility for itself. With social infantilism, confrontation is associated with everything that goes beyond the boundaries of the community, preventing the formation of civil identity. For example, despite the cordial welcome that the Pashtuns provided to the guest in their home, the same guest was robbed to the outside of his village.

Thus, the population of the country differs in physical and anthropological features, language, culture, and a level of social and economic development.

Despite the heterogeneous ethnic composition of the population of Afghanistan, the overall ethnic and political situation in the country is determined by the Pashtuns and Tajiks, who together account for more than $60 \%$ of the population [10]. The specificity of the nature and economic activity has left the imprint on the relationship between these peoples characterized by antagonism and hostility. The Pashtuns had long been engaged in nomadic cattle breeding in the spurs of the Suleiman Mountains, while the Tajiks were engaged in agriculture in the Kandahar plain.

It is important to compare these economic and cultural types. The pastoralists and nomads preserve the archaic features of their way of life. Their consciousness and behavior have primitive origins. The Nomadic tribes have preserved a stable tribal structure. The Pashtuns has a feeling of respect for the fellow tribesmen, which is expressed in the principle of 'Musavat' according to which all Pashtuns are brothers. The blood vengeance and the intolerance to insult is the law of the Pashtuns.

The life of nomads is based on the management of herds of animals and in military clashes. War is the way of their existence and an integral element of both economic and spiritual life. Therefore, cultivation of aggressiveness (the valor of a true warrior) is typical for the pastoralists-nomads.

Since childhood, the Pashtuns have been taught that victory or death during the battle is an honor. The Pashtuns are very good at weapons and never part with it. They do not express despair about the death of loved ones in the war, because the business of the deceased would be continued by his relatives. In the education of children, no distinction is made between boys and girls. A.B. Orishev notes that "women are also subject to the requirement to be courageous and participate in battles on equal terms with men' [9]. Aggressiveness is not the inborn quality of the Pashtuns, but the cultural quality of the ethnos formed by the way of life. Predatory wars are of great importance in the life of nomads, determining the difference between their lives and the life of farmers.

Considering the relationship of the Tajiks and the Pashtuns R.M. Mahmadshoev notes that 'the name' Afghanistan 'comes from the Tajik word 'Afghan', which means moaning, crying, yelling. The formidable nomadic Pashtun tribes had been living to the south of
Kandahar and the spurs of the Suleyman Mountains for a long time. They did not miss a single traveler or a commercial caravan to avoid robbing, killing or taking them as prisoners' [8]. In nomadic tribes, the number of armed detachments comprises up to $20 \%$ of the population. Their military training is not inferior to regular troops [7]. There is a taught discipline among armed detachments and in case it is violated the severe punishments are applied. At times it may even be a death penalty.

Practical and productive work formed the attitude among farmers towards the war as something indispensable. For example, Tajiks who live in inaccessible natural fortresses to the north-east of Kabul in Panjshir and Badakhshan, despite their belligerence, are so attached to home that they are incapable of active offensive actions. Farmers are very peaceful people; they are interested in the united economic and political space. Therefore, according to A.Yu. Umnov 'the Pashtuns who aspired to centralization relied not on the relatives that were inclined to isolation, but on the Tajiks ...' [10].

Unlike nomads moving in space, farmers move in time. That is why a continuous development is identified as their distinctive feature. Therefore, agricultural life was more progressive. In spite of the historical fact that the nomads, as a rule, defeated the farmers in military battles, but after the victory they adopted the way of life of the farmers and the nomadic existence was preserved in the army.

So, in order to secure the annexed non-Pashtun territories, the Kabul emirs moved the Pashtuns giving them the best irrigated lands. As a result, Pashtun settlers had changed to a settled way of life, contributing to a general economic recovery and increased tax collections [2].

Freedom is one of the most important characteristics of the culture of nomadic peoples. Without analyzing the dialectic of this characteristic, let's pay attention to the fact that Pashtuns value their freedom. A.A. Lyakhovsky in his article, referring to A.E. Snesarev, quotes the words of the Pashtun addressed to the Englishman: 'Let us be poor and let our blood flow ... this is our internal business. The Afghans are free people' [7]. Therefore, a foreign presence in Afghanistan is a factor of destabilization that prevents the formation of a national identity.

Among the political factors hampering the formation of national identity is the discriminatory policy of the ruling Pashtun leadership regarding ethnic minorities.

The ethnic component plays an important role in the Afghan society. The political parties were also established on the basis of ethnicity. The ladder of the social hierarchy of the Afghan society is represented in the study of Yu.P. Laletin: '... the Pashtuns are on the upper step, then come the Tajiks, then - the Baloch, Nuristani, Uzbeks, Turkmens, etc., and the Hazaras are at the very bottom. From the ethnic point of view the social pyramid in the pre-revolutionary Afghanistan (before 1978) was presented as follows: the upper tier the Pashtuns military-political power; below is the Pashtun-Tajik major commercial and industrial bourgeoisie ...; further - the middle and small 
predominantly non-Pashtun bourgeoisie (about half of them are Tajiks ...). The intelligentsia is concentrated mainly in the Tajik-Pashtun composition at all levels; at the base of the social pyramid there are the working people and the semi-proletarian strata (2/3 of the factory working class consisted of non-Pashtun elements ...)'[6].

The elite plays an important role in the formation of national identity. In the $\mathrm{XX}^{\text {th }}$ century, the non-Pashtun intelligentsia had been actively developing. In the 20s of the $\mathrm{XX}^{\text {th }}$ century the schools of modern type were established in Northern Afghanistan, and the lyceums were built in the cities of Mazar-i-Sharif and Khanabad. The first modern secondary and vocational schools were established in the north of Afghanistan in the 70s of the $\mathrm{XX}^{\text {th }}$ century. One of them was the Pedagogical Institute in the city of Maiman, where in 1980s the Department of Uzbek Language and Literature was established. Balkh University was later founded on the basis of this institute. In 1971, the Oil and Gas Institute was opened in Mazar-i-Sharif, as well as the Technical School for training of oil specialists and mining engineers.

In 1989, out of the 22,000 teachers more than 15,000 were Tajiks and about 1,000 were Uzbeks, while Pashtuns numbered over 5,000 [1].

The development of elites of national minorities is evidenced by numerous facts (studies of Yu.P. Laletin). For example, after 1978 the first Uzbek newspaper, Yulduz (the Star) was published in Afghanistan; television and radio were broadcast in the Uzbek language; books and teaching materials were also published in the Uzbek language. Poems of modern Uzbek poets of Afghanistan appeared in the press. The first research of oral folk art of Uzbeks in the northern provinces of Afghanistan has appeared. The development of modern Tajik and Uzbek intellectuals was supported by the expansion of cultural ties between the northern provinces of Afghanistan and the republics of the Soviet Union. The social and cultural changes taking place in Afghanistan in the 1980s had officially enshrined in the country's basic law, the right of citizens to receive education in their native language contributed to the development of Uzbek written literature. The first Uzbek literary, as well as cultural and educational public organizations were established. In the 40s and especially 60 s of the $\mathrm{XX}^{\text {th }}$ century, the political groups and parties had been actively developing (the Wish Zalmian movement (Awakened Youth), which included the Tajik Mohammed Naim Shayan). In March 1951, a newspaper was published in Kabul Vatan (Motherland) on the basis of which a political movement under the same name was being formed, which included the representatives of nonPashtun peoples, mainly Tajiks. The Islamic Society of Afghanistan was of great importance in the process of consolidation of the Tajiks, which after the events of April 1978 became one of the most significant detachments of the opposition. On the territory of the whole country, this party created bodies of civil and military power. The consolidation of ethnic minorities was accompanied by the weakening of the Pashtuns [5].

Thus, as a result of social and political, as well as demographic changes, the role of non-Pashtun ethnic groups has increased; moreover, their quantitative component has grown. The reduction of the Pashtun population in the country's population was accompanied by a decrease in their level of education. Currently, A. Knyazev draws attention to the fact that in Kabul universities up to $80 \%$ of students are Hazaras who were 100 years ago a discriminated and poorly educated minority. Young Pashtuns are replenishing the ranks of illiterate militants [3]. The weakening of the Pashtun ethnos along with the consolidation of the ethnic minorities allowed the elite of the North to claim power on a national scale against which the Pashtuns actively and militantly advocate. As a result, the political conflict takes the ethnic confrontation form.

Thus, the Afghan society is fragmented and represents a combination of different types of social ties. The ethnohierarchical set of society leads to a permanent interethnic confrontation.

The discord and mutual distrust turning into the enmity and suspicion towards the central government may result in the disintegration of the State. This trend became particularly noticeable after the withdrawal of the Soviet troops and transfer of armed struggle to the local level.

\section{References}

1. L.B. Aristova, Yu.V. Bossin, M. Makhkamov, H. Hashimbekov, Multinational Afghanistan, Western Asia: Ethnopolitical Situation. (Moscow, 1993)

2. A. Knyazev, Separation of Afghanistan will cause "domino effect" for Central Asia in general, regnum.ru (10.09.2016)

3. A. Knyazev, There is another round of sharp interethnic confrontation in Afghanistan, ROOT in EXPERTISE, THE MAIN (TwitterFacebook, 2017)

4. Yu. Laletin, Ethnoses in Afghanistan: tension of relationship Retrieved from: mgimo.ru

5. Yu. Laletin, Interethnic interaction in Afghanistan, Conflicts in the East: Ethnic and Confessional. (Moscow: Aspect press, 2008)

6. A.V. Loginov, The national issue in Afghanistan, Races and peoples. (Moscow, 1990)

7. A. Lyakhovsky, Tragedy and valor of Afghanistan, Retrieved from: litmir.me

8. R. Makhmadshoev. The Tajiks and Pashtuns: issues of relationships, Retrieved from: nsu.ru

9. A. Orishev, Pashtunvali - the history of life and philosophy of Pashtuns, Retrieved from: ppcademy.ru

10. A. Umnov, Afghanistan: issues and prospects, Retrieved from: limes.ru 